\title{
Genetic Algorithm Parameter Optimization using Taguchi Robust Design for Multi-response Optimization of Experimental and Historical Data
}

\author{
Abhishek Majumdar \\ B.Tech., Dept of Electronics \& Communication \\ Engg. Indian Institute of Technology Roorkee, \\ Rookee 247667, India
}

\author{
Debashis Ghosh \\ Professor, Department of Electronics \& \\ Communication Engg, Indian Institute Technology \\ Roorkee Roorkee 247667, India
}

\begin{abstract}
This paper presents a methodology for robust optimization of Genetic Algorithm (GA) involving complex interactions among the control parameters. Finding the Optimum GA parameters to solve an optimization problem for producing best results with least variability is still an open area of research.
\end{abstract}

The proposed research approach primarily covers the robust optimization of Genetic Algorithm control parameters using Taguchi Design of Experiment (DOE) with a special set of L25 orthogonal array (OA). The experimental design and the study is conducted with MATLAB Genetic Algorithm internal control parameters using real-coded Genetic Algorithm fitness functions operates directly on real values of two different case studies. One of them is based on experimental data for the development of a new product and the other one is based on the historical data of an existing product under large scale complex manufacturing system. The performance characteristics (Best fitness value) of GA are evaluated. The main effect for signal-to- noise ratios (SNR), main effect for means, response tables and analysis of variance (ANOVA) are employed and optimum parameter settings are obtained. The confirmation experiments are carried out with the optimum setting parameters and the results are compared with the predicted \& default setting values of GA.

The experimental results show an increase of signal-to-noise ratio (SNR) by around $54 \%$ and mean by 12 to $25 \%$ from the default setting of GA to the optimum settings arrived during the experimental process, which are extremely significant. Further, cross over was found to be the most influential parameter for both the case studies, followed by other parameters like population size, selection process for case study- 1 and mutation rate, population size for case study-2. It is evident that the GA performances are also sensitive to the objective function (transfer function in GA terms).

The study clearly shows the robust optimization of GA parameters leading to best level of performance characteristics with least variability for the solution of real life optimization problem, using Taguchi Experimental Design Techniques.

\section{Keywords}

Genetic Algorithm (GA), Parameter Optimization, Taguchi Robust Design, Design of Experiments (DOE), ANOVA, Experimental and Historical data.

\section{INTRODUCTION}

Genetic algorithm (GA) is one of the most widely used and popular form of evolutionary algorithms for solving global search and multidimensional complex optimization problems.
The GA exhibits a number of control parameters, such as population size, fitness function, selection method, mutation, crossover, generations and others. Literature search shows extensive studies on GA parameters, their interactions and values. Some researchers (Goldberg, Deb, and Clark, 1992; Harik et al., 1997) focused on the study for evaluating the impact of important parameters such as population size on the performance of GA[1]. The dynamics of the GA parameter interactions were also studied using Markov chains and analyzed (Chakraborty, Deb, and Chakraborty, 1996; Nix and Vose, 1992; Suzuki, 1993; Vose, 1992)[2]. Deb K and Agarwal S (1999) suggested that for solving simple problems (unimodal or small modality problems), mutation operator plays an important role and for complex problems involving massive multimodality, crossover operator is the key search operator [3]. Some researchers worked for the best settings of control parameters. Several studies continued with the effect of parameter settings and its relative importance $[4,5,6,7,8,9]$.

One of the challenging aspects of GA is its number of control parameters with each of the parameters having number of levels (functions and options) and the complex interactions between them. Hence there are large number of combinations in GA parameters and it is extremely difficult to evaluate the effects of parameters settings on GA performances. Therefore, there is a need for a robust and effective way to determine the statistically significant GA parameters \& their levels. Taguchi robust experimental design is one of the most effective methods for arriving at the robust parameter setting of such problems with least number of experiments $[10,11,12,13,14]$.

The present work proposes a systematic procedure and the statistical methodology of Taguchi robust optimization design L25 orthogonal array (OA) for evaluating the best factor-level combinations of GA parameters with its application on two case studies of multi-response optimization problems with real coded GA and real values.

\section{BASIC THEORY - AN OVERVIEW}

Prof. Holland (1974) from the University of Michigan developed the ideas and concepts GA based on the principles of Genetics and Natural Selection "survival of the fittest" and many authors have refined his initial approach. Genetic algorithms imitate the evolutionary process of species and natural selection by a computer program. A very important point to note that GA searches the solution space by maintaining a population of potential solutions and is less likely to get trapped at a local optimum. Each individual in the population is referred as a chromosome. The genetic information of the chromosome is encoded using an appropriate method (Eg. Binary Encoding, Hexadecimal Encoding, Tree, etc.), representing a solution to the given problem. These chromosomes then evolve through successive 
iterations, called generations and subsequently follows certain steps. The details are explained through the flow chart shown in Figure 1

\subsection{Key Elements of Genetic Algorithm (GA) :}

The various parameters essential for running GA along with the options referred in MATLAB are as under :

The Fitness Function: The fitness function in Genetic Algorithm represents the objective function and the fitness value corresponds the performance of an individual chromosome. Population: Population is a collection of individuals. Population specifies the options for the population size in GA. The two important aspects are the initial population generation and the population size. Fitness Scaling: Fitness scaling is performed in order to avoid premature convergence and slow finishing. Some of its types are Rank, proportional, top qty, shift linear etc. Selection (Reproduction): Selection is the process of choosing two parents from the population for crossing. Some of the various selection methods are stochastic uniform, remainder, roulette wheel selection, random selection, rank selection,

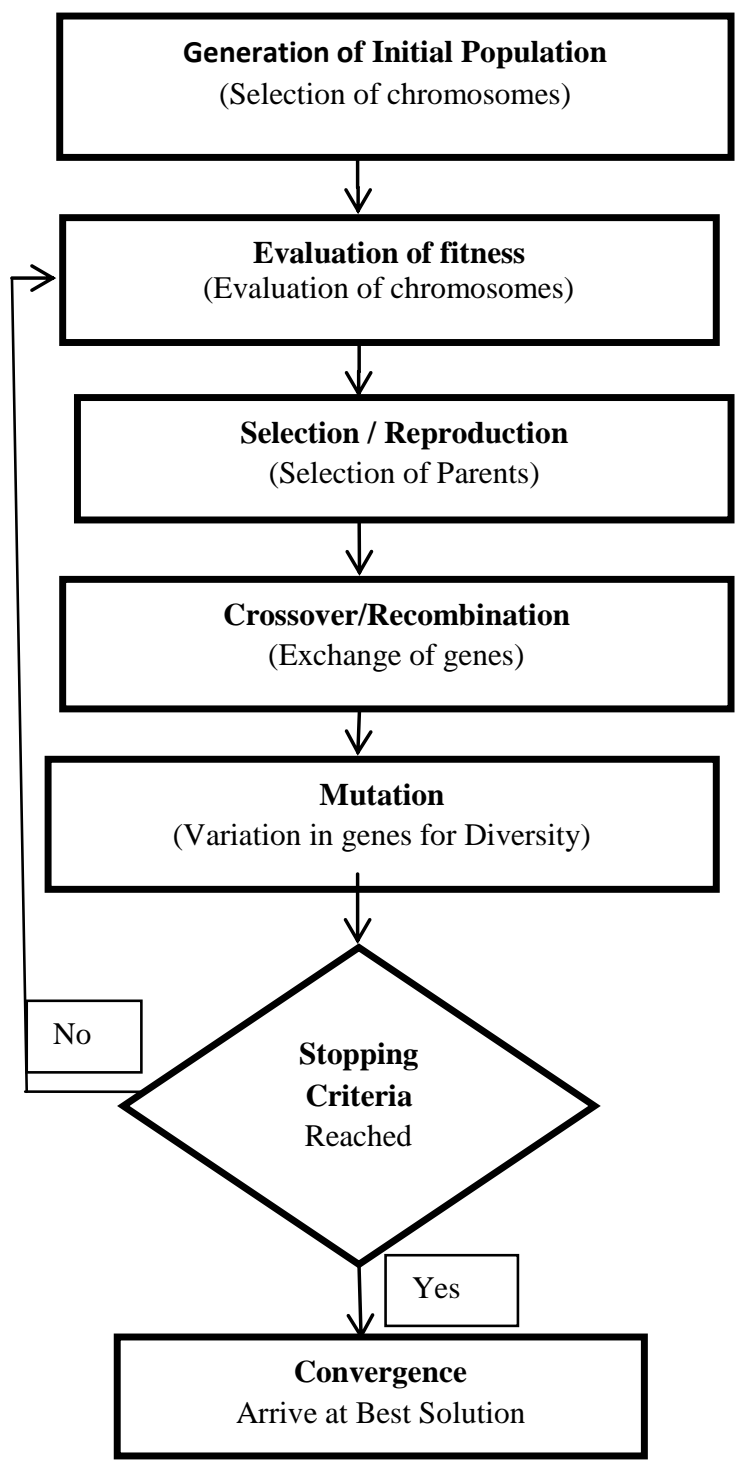

Figure 1 : Flowchart of Genetic Algorithm( GA) tournament selection, elitism etc. Crossover (Recombination): Crossover combines two individuals, or parents, to form a new individual, or child, for the next generation. Some of its types are scattered, single point crossover, two point crossover, intermediate, heuristic, arithmetic etc. Mutation: After crossover, the springs are subjected to mutation. Mutation functions make small random changes in the individuals in the population, which provide genetic diversity and enable the genetic algorithm to search a broader space. The different forms of mutation are constraint dependent, uniform, adaptive feasible etc. Mutation of a bit involves flipping it, changing between 0 to 1 and vice versa with a small mutation probability. Stopping criteria: Stopping criteria determines what causes the algorithm to terminate-generations, time limit, fitness limit etc.

\subsection{An Overview of Taguchi Robust Design Experiment}

Taguchi Robust Design Experiment Strategy uses the integration of two primary concepts: Signal-to-Noise Ratio (SNR) and Design of Experiments using Orthogonal Array $(\mathrm{OA})$. OA provides a set of well balanced minimum number of experiments and Signal-to-Noise ratios $(\mathrm{S} / \mathrm{N})$ serve as objective functions for optimization, help in data analysis and prediction of optimum results.

a. Signal to Noise $(S / N)$ Ratios: Signal-to-noise ratio is the measure of robustness of a product or process or system and the design optimization problem can be solved in two steps: a) Maximize the $\mathrm{S} / \mathrm{N}$ ratio and b) Adjust the mean on target using a control factor. A number of different SN Ratios have been defined by Dr. Taguchi, but the most important three are Larger-the-Better(LTB), Smaller-the-Better(STB) and Nominal-the Best(NTB). The NTB type has been used for this study, which is defined as

S/N Ratio $(\eta)=10 \log _{10}\left(\frac{\mu^{2}}{\sigma^{2}}\right)$

where $\mu=$ mean, $\sigma=$ standard deviation. The $\mathrm{SN}$ ratio is always expressed in decibel $(\mathrm{dB})$ unit. A higher value of SN ratio implies a lower value of quality loss and hence a better quality of product.

\section{b. Design of Experiments using Orthogonal Array} $(O A)$ : Dr. Taguchi has developed a novel experimental method based on Orthogonal Array (OA), which is a method of designing experiments that usually requires only a fraction of the full factorial combination. In the Taguchi design, the array is orthogonal, which means the design is balanced so that the factor levels are weighted equally and each factor can be evaluated independently of all other factors. While there are many standard orthogonal arrays available, each of the arrays is meant for a specific number of independent design variables and levels. The design of experiments using the orthogonal array is, in most cases, efficient when compared to many other statistical designs.

\section{PROPOSED APPROACH}

The proposed approach consists of three phases: Phase 1: Research design and framework, Phase 2: Experimentation for Optimizing the Performance Metric (Best Fitness Value), Phase 3: Results and discussions.

First phase involves study of the behavior of internal control parameters of Genetic Algorithm and plan for the research design based on Taguchi Robust Design (L25). The second phase involves conducting experiments \& evaluation of the 
fitness function. Finally, the third phase consists of the Analysis and interpretations.

\section{EXPERIMENTAL DETAILS}

\subsection{Research design and framework}

This phase involves literature search, study of the behavior of MATLAB Genetic Algorithm control parameters, conducting screening test with those parameters and plan for the factorlevel combinations based on Taguchi Robust Design. Key steps of this phase are as follows:

Step 1. Identification of the significant control parameters and their levels: Five MATLAB GA control parameters as factors and each at five levels are identified for this study. Details of the control parameters and their levels chosen are shown in the Table 1

Table 1: Factors and their levels (Matlab genetic algorithm parameters)

\begin{tabular}{|c|c|c|c|c|c|c|}
\hline \multicolumn{2}{|c|}{ Factors } & \multicolumn{5}{c|}{ Levels } \\
\hline Code & GA Parameters & 1 & 2 & 3 & 4 & 5 \\
\hline A & Population Size & 20 & 30 & 40 & 45 & 50 \\
\hline B & $\begin{array}{c}\text { Fitness scaling } \\
\text { Function }\end{array}$ & Rank & Proportional & Top Qty 0.2 & Top Qty 0.4 & Shift Linear \\
\hline C & Selection Function & $\begin{array}{c}\text { Stochastic } \\
\text { Uniform }\end{array}$ & Remainder & Uniform & Roulette & Tournament \\
\hline D & Mutation Function & $\begin{array}{c}\text { Constraint } \\
\text { Dependent }\end{array}$ & $\begin{array}{c}\text { Uniform rate } \\
0.01\end{array}$ & Uniform rate 0.05 & Uniform rate 0.1 & $\begin{array}{c}\text { Adaptive } \\
\text { feasible }\end{array}$ \\
\hline E & Crossover Function & Scattered & Two Point & Intermediate ratio 1.0 & Heuristic ratio 1.2 & Arithmetic \\
\hline \multicolumn{7}{|c|}{ Note : Stopping criteria - No of generations till auto termination takes place with MATLAB default setting of 100 } \\
\hline
\end{tabular}

Step2. Identification of response variable: GA output parameter "Best Fitness" is considered as response variable for this study. Multi-response weighted signal-to-noise ratio (MRWSN) for the experimental data of the new product and Overall Desirability ( OD ) for the historical data of existing product are the Best Fitness functions for the respective case studies.

Step3. Selection of appropriate Design of Experiments ( DOE ): Taguchi Robust experimental design with L25 orthogonal array layout is chosen for the set of experiments. Details of the experimental layout are shown in the Table2.

Step4. Measure of robustness for the objective function: Signal-to-Noise ratio "Nominal the best" is considered as the measure of robustness for this study .

Step 5. Objective Functions (Fitness Functions): The objective functions used for this case studies are defined using the MTALAB codes developed for the multi-response optimization of two case studies- Case study1 and Case study2. The objective functions (transfer function in GA terms) are shown in the Table 3 and Table 4 respectively.

Table 2. Experimental layout : Taguchi L25 OA

\begin{tabular}{|c|c|c|c|c|c|}
\hline \multirow{2}{*}{ SI No } & \multicolumn{5}{|c|}{$\begin{array}{c}\text { Experimental Factors } \\
\text { ( GA Parameters ) }\end{array}$} \\
\cline { 2 - 6 } & A & B & C & D & E \\
\hline 1 & 1 & 1 & 1 & 1 & 1 \\
\hline 2 & 1 & 2 & 2 & 2 & 2 \\
\hline 3 & 1 & 3 & 3 & 3 & 3 \\
\hline 4 & 1 & 4 & 4 & 4 & 4 \\
\hline 5 & 1 & 5 & 5 & 5 & 5 \\
\hline 6 & 2 & 1 & 2 & 3 & 4 \\
\hline 7 & 2 & 2 & 3 & 4 & 5 \\
\hline 8 & 2 & 3 & 4 & 5 & 1 \\
\hline 9 & 2 & 4 & 5 & 1 & 2 \\
\hline
\end{tabular}

\begin{tabular}{|l|l|l|l|l|l|}
10 & 2 & 5 & 1 & 2 & 3 \\
\hline 11 & 3 & 1 & 3 & 5 & 2 \\
\hline 12 & 3 & 2 & 4 & 1 & 3 \\
\hline 13 & 3 & 3 & 5 & 2 & 4 \\
\hline 14 & 3 & 4 & 1 & 3 & 5 \\
\hline 15 & 3 & 5 & 2 & 4 & 1 \\
\hline 16 & 4 & 1 & 4 & 2 & 5 \\
\hline 17 & 4 & 2 & 5 & 3 & 1 \\
\hline 18 & 4 & 3 & 1 & 4 & 2 \\
\hline 19 & 4 & 4 & 2 & 5 & 3 \\
\hline 20 & 4 & 5 & 3 & 1 & 4 \\
\hline 21 & 5 & 1 & 5 & 4 & 3 \\
\hline 22 & 5 & 2 & 1 & 5 & 4 \\
\hline 23 & 5 & 3 & 2 & 1 & 5 \\
\hline 24 & 5 & 4 & 3 & 2 & 1 \\
\hline 25 & 5 & 5 & 4 & 3 & 2 \\
\hline
\end{tabular}

Table 3. Multi-response optimization equation of Weighted Signal to Noise for GA code : Case study-1

\begin{tabular}{|c|}
\hline $\mathrm{MRWSN}=0.2 * \mathrm{SN}(\mathrm{TL})+0.4 * \mathrm{SN}(\mathrm{a})+0.4 * \mathrm{SN}(\mathrm{b})$ \\
\hline Y1 Avg $($ TL $)=76.6-0.945 \times 1-2.27 \times 2-0.268 \times 3-3.21 \times 4$ \\
\hline Y2 Avg $(a)=-5.98-0.307 \times 1-0.135 \times 2+0.304 \times 3+1.43 \times 4$ \\
\hline Y3 Avg $(b)=-3.50+0.346 \times 1-1.76 \times 2+0.446 \times 3+2.39 \times 4$ \\
\hline $\begin{array}{l}\log 10(\text { Y1 var })=-1.80+0.275 \times 1+0.0755 \times 2-0.0403 \times 3-0.0159 \\
x 4\end{array}$ \\
\hline $\begin{array}{l}\log 10(Y 2 \text { var })=-2.52+0.0375 \times 1+0.103 \times 2+0.0064 \times 3+0.0045 \\
x 4\end{array}$ \\
\hline $\begin{array}{l}\log 10(\text { Y3 var })=-1.81-0.0813 \times 1-0.0010 \times 2-0.0001 \times 3+0.0882 \\
x 4\end{array}$ \\
\hline Symbol Definitions : \\
\hline
\end{tabular}




\subsection{Experimentation for Optimizing the Performance Metric (Best Fitness Value):}

This phase primarily aims to conduct the planned experiments (computerized simulations) for maximizing the fitness function and arriving at the best fitness value with least variability \& optimal combination of the parameters within the specified range of operations. The study is conducted with the MATLAB Genetic Algorithm control parameters using real-coded Genetic Algorithm fitness functions that operates directly on real values of two different case studies. One of them is based on experimental data for the development of a new product and the other one is based on the historical data of an existing product under large scale complex manufacturing system. The performance characteristics (Best fitness value) of GA are evaluated.

Table 4. Multi-response optimization equation of overall desirability (OD) used for writing GA code : Case study - 2

\author{
GA Code for the Overall Desirability, \\ $\mathrm{OD}=0.5 * \mathrm{~d}(\mathrm{a})+0.3 * \mathrm{~d}(\mathrm{~b})+0.2 * \mathrm{~d}(\mathrm{RL})$ \\ Y1(a) $=35.3-0.0433 \times 1-0.0293 \times 2-0.00389 \times 3+0.0830 \times 4+0.0089 \times 5-0.0222 \times 6-1.22 \times 7$ \\ $Y 2(b)=-26.4+0.00125 \times 1+0.0867 \times 2-0.169 \times 3-0.352 \times 4+0.0268 \times 5+0.486 \times 6+4.39 \times 7$ \\ Y3 $(R L)=22.9-0.0144 \times 1+0.0175 \times 2-0.00207 \times 3+0.0295 \times 4+0.00489 \times 5-0.00009 \times 6-1.04 \times 7$ \\ Symbol Definitions : \\ a, b : Colour Space Co-Ordinates , RL : Reflection of Light , d : Individual Desirability
}

\section{RESULTS AND DISCUSSIONS 5.1. Descriptive statistics of experimental results:}

All the experiments of 5 replicates are conducted based on the L25 orthogonal array layout and the responses of both the case studies (WSN GA Best Fitness and Overall Desirability Fitness values) are shown in the Table 5 and Table 6 respectively.

\subsection{Analysis and Interpretations: MINITAB} 16 is used to analyze the data.

\subsubsection{Analysis for optimum level of control} factors: In order to identify the optimum levels of control factors, signal-to-noise ratio and analysis of means are done.

\subsubsection{Analysis of Signal-to-Noise ratio and Mean}

$\therefore$ Signal-to-Noise ratio is calculated for the Nominal-The-Best type problem, which have been incorporated in the MATLAB GA code. The response tables and main effect plots for SN ratios and Mean are analyzed. The rank and optimum combination of the parameters are obtained and shown in the Table 7 and Table 8 respectively.

\subsubsection{Selection of the optimum levels of control} factors: Values for the importance of the ranks for SN ration and Mean are analyzed. The optimum combinations of control factors are arrived as A5B3C2D5E4 and
A4B4C3D1E4 for the respective case studies and shown in the bottom row of the Table 7 and Table 8 respectively.

5.2.1.3 The predicted values: The predicted values of SN Ratio and Mean for the optimum combinations of control factors are shown in the Table 11

5.2.2 Analysis of Variance (ANOVA): Analysis of variance is done to evaluate the magnitude of the contribution (\%) of each control parameter on the response parameter. The percentage contribution by each of the process parameter in the total sum of square deviation(SST) is a ratio of the sum of square deviation (SSD) due to each process parameter to the total sum of square deviation(SST). It is seen in the ANOVA Table 9 that the crossover function (E) is having the highest contribution as $37.72 \%$, followed by population size (A) as $27.57 \%$ and selection function (C) as $16.0 \%$, with mutation function(D) and fitness scaling function (B) ranking fourth and fifth respectively. Details in the ANOVA Table10 shows that the crossover function $(\mathrm{E})$ is having the highest contribution as $45.11 \%$, followed by mutation function (D) as $23.37 \%$ and population size (A) as $16.3 \%$, with fitness scaling function (B) and selection function (C) ranking fourth and fifth respectively.

\section{CONFIRMATION EXPERIMENTS}

Confirmation experiments of 15 simulation runs for each case study are carried out with the optimum setting along with the default setting parameters of MATLAB GA and the results are shown in the Table 11. The response values for optimum combination of levels as validated was compared with the optimum combination of levels as predicted and the default setting values. The performances are found to be in close agreement. 
Table 5. Response variable MRWSN GA best fitness : Case study-1

\begin{tabular}{|c|c|c|c|c|c|c|c|}
\hline $\begin{array}{c}\text { SI } \\
\text { No }\end{array}$ & $\mathbf{R 1}$ & $\mathbf{R 2}$ & $\mathbf{R 3}$ & $\mathbf{R 4}$ & $\mathbf{R 5}$ & $\begin{array}{c}\text { Avg } \\
\text { Resp } \\
\text { onse }\end{array}$ & SNR \\
\hline 1 & 33.24 & 34.06 & 33.50 & 33.14 & 33.06 & 33.40 & 38.34 \\
\hline 2 & 33.56 & 32.97 & 33.44 & 33.45 & 33.30 & 33.34 & 43.21 \\
\hline 3 & 32.89 & 32.96 & 33.12 & 33.16 & 32.71 & 32.97 & 45.17 \\
\hline 4 & 33.83 & 33.71 & 33.26 & 34.12 & 34.08 & 33.80 & 39.71 \\
\hline 5 & 32.38 & 33.78 & 33.19 & 33.96 & 33.77 & 33.42 & 34.25 \\
\hline 6 & 34.28 & 34.32 & 34.32 & 34.28 & 34.28 & 34.29 & 64.41 \\
\hline 7 & 32.29 & 33.36 & 32.71 & 32.30 & 32.86 & 32.70 & 37.31 \\
\hline 8 & 34.24 & 34.26 & 34.30 & 34.21 & 34.31 & 34.26 & 58.30 \\
\hline 9 & 34.29 & 34.08 & 34.25 & 34.24 & 34.07 & 34.19 & 50.59 \\
\hline 10 & 32.58 & 32.80 & 32.60 & 32.44 & 32.10 & 32.50 & 41.93 \\
\hline 11 & 33.52 & 33.23 & 33.29 & 33.48 & 33.98 & 33.50 & 41.06 \\
\hline 12 & 33.12 & 32.83 & 33.43 & 33.27 & 33.15 & 33.16 & 43.47 \\
\hline 13 & 34.17 & 34.01 & 33.97 & 33.77 & 33.99 & 33.98 & 47.41 \\
\hline 14 & 33.28 & 33.70 & 33.87 & 33.12 & 33.59 & 33.51 & 40.74 \\
\hline 15 & 34.00 & 34.23 & 33.91 & 34.04 & 34.06 & 34.05 & 49.33 \\
\hline 16 & 33.72 & 33.32 & 33.53 & 33.26 & 33.57 & 33.48 & 44.91 \\
\hline 17 & 34.16 & 33.74 & 34.04 & 34.01 & 33.84 & 33.96 & 46.23 \\
\hline 18 & 34.15 & 33.89 & 34.10 & 34.10 & 34.12 & 34.07 & 50.24 \\
\hline 19 & 34.14 & 34.02 & 33.85 & 33.90 & 33.97 & 33.98 & 49.60 \\
\hline 20 & 34.26 & 34.03 & 34.07 & 34.22 & 34.24 & 34.17 & 50.32 \\
\hline 21 & 33.98 & 34.00 & 34.04 & 34.10 & 33.99 & 34.02 & 56.90 \\
\hline 22 & 34.29 & 34.29 & 34.28 & 34.25 & 34.24 & 34.27 & 63.57 \\
\hline 23 & 34.02 & 34.04 & 34.05 & 34.26 & 34.09 & 34.09 & 50.73 \\
\hline 24 & 34.02 & 33.83 & 34.09 & 33.72 & 34.25 & 33.98 & 44.24 \\
\hline 25 & 33.88 & 34.21 & 34.19 & 34.19 & 34.08 & 34.11 & 47.67 \\
\hline & & & & & & & \\
\hline 12 & & & \\
\hline
\end{tabular}

Table 6. Response variable for Overall Desirability (OD) : Case study-2

\begin{tabular}{|c|c|c|c|c|c|c|c|}
\hline $\begin{array}{c}\text { SI } \\
\text { No }\end{array}$ & $\mathbf{R 1}$ & $\mathbf{R 2}$ & $\mathbf{R 3}$ & $\mathbf{R 4}$ & $\mathbf{R 5}$ & $\begin{array}{c}\text { Avg } \\
\text { Response }\end{array}$ & SNR \\
\hline 1 & 0.592 & 0.746 & 0.580 & 0.730 & 0.713 & 0.672 & 18.525 \\
\hline 2 & 0.470 & 0.638 & 0.546 & 0.409 & 0.312 & 0.475 & 11.592 \\
\hline 3 & 0.444 & 0.477 & 0.455 & 0.531 & 0.585 & 0.498 & 18.554 \\
\hline 4 & 0.690 & 0.613 & 0.547 & 0.534 & 0.633 & 0.603 & 19.467 \\
\hline 5 & 0.587 & 0.390 & 0.556 & 0.577 & 0.465 & 0.515 & 15.658 \\
\hline 6 & 0.766 & 0.766 & 0.814 & 0.681 & 0.604 & 0.726 & 18.793 \\
\hline 7 & 0.511 & 0.443 & 0.448 & 0.452 & 0.544 & 0.480 & 20.494 \\
\hline 8 & 0.609 & 0.727 & 0.723 & 0.549 & 0.578 & 0.637 & 17.712 \\
\hline 9 & 0.584 & 0.756 & 0.749 & 0.766 & 0.656 & 0.702 & 18.925 \\
\hline 10 & 0.401 & 0.395 & 0.436 & 0.515 & 0.582 & 0.466 & 15.231 \\
\hline 11 & 0.565 & 0.627 & 0.712 & 0.498 & 0.554 & 0.591 & 17.201 \\
\hline 12 & 0.422 & 0.575 & 0.436 & 0.481 & 0.479 & 0.479 & 18.061 \\
\hline 13 & 0.584 & 0.618 & 0.653 & 0.743 & 0.509 & 0.618 & 17.094 \\
\hline 14 & 0.568 & 0.589 & 0.587 & 0.647 & 0.446 & 0.567 & 17.689 \\
\hline 15 & 0.457 & 0.673 & 0.662 & 0.648 & 0.715 & 0.631 & 15.963 \\
\hline 16 & 0.557 & 0.481 & 0.522 & 0.485 & 0.405 & 0.490 & 18.738 \\
\hline 17 & 0.654 & 0.513 & 0.670 & 0.643 & 0.495 & 0.595 & 17.019 \\
\hline 18 & 0.732 & 0.708 & 0.650 & 0.573 & 0.660 & 0.665 & 20.696 \\
\hline
\end{tabular}

\begin{tabular}{|l|l|l|l|l|l|l|l|}
19 & 0.725 & 0.600 & 0.698 & 0.582 & 0.595 & 0.640 & 19.695 \\
\hline 20 & 0.807 & 0.848 & 0.832 & 0.821 & 0.673 & 0.796 & 21.058 \\
\hline 21 & 0.725 & 0.568 & 0.554 & 0.692 & 0.606 & 0.629 & 18.365 \\
\hline 22 & 0.782 & 0.731 & 0.683 & 0.598 & 0.804 & 0.720 & 18.805 \\
\hline 23 & 0.741 & 0.663 & 0.607 & 0.595 & 0.597 & 0.641 & 20.196 \\
\hline 24 & 0.599 & 0.677 & 0.537 & 0.533 & 0.670 & 0.603 & 18.799 \\
\hline 25 & 0.614 & 0.724 & 0.670 & 0.614 & 0.513 & 0.627 & 18.058 \\
\hline
\end{tabular}

Table 7: optimum combination of parameters from response table-(MRWSN) : Case study-1

\begin{tabular}{|c|c|c|c|c|c|c|}
\hline \multirow{2}{*}{ Rank } & SN Ratio & 2 & 4 & 3 & 5 & 1 \\
\cline { 2 - 7 } & Mean & 2 & 5 & 3 & 4 & 1 \\
\hline \multirow{2}{*}{$\begin{array}{c}\text { Optimum } \\
\text { Level }\end{array}$} & SN Ratio & 5 & 3 & 2 & 5 & 4 \\
\cline { 2 - 7 } & Mean & 5 & 4 & 2 & 5 & 4 \\
\hline $\begin{array}{c}\text { Adjustme } \\
\text { nt }\end{array}$ & $\begin{array}{c}\text { Vari } \\
\text { abili } \\
\text { ty }\end{array}$ & $\begin{array}{c}\text { Vari } \\
\text { abili } \\
\text { ty }\end{array}$ & $\begin{array}{c}\text { Vari } \\
\text { tyili } \\
\text { ty }\end{array}$ & Mean & $\begin{array}{c}\text { Varia } \\
\text { bility }\end{array}$ \\
\hline $\begin{array}{c}\text { Optimum } \\
\text { Combinati } \\
\text { on }\end{array}$ & A5 & B3 & C2 & D5 & E4 \\
\hline
\end{tabular}

Table 8. Optimum combination of parameters from response table - (OD) : Case study-2

\begin{tabular}{|c|c|c|c|c|c|c|}
\hline \multirow{2}{*}{ Rank } & SN Ratio & 2 & 5 & 3 & 1 & 4 \\
\cline { 2 - 7 } & Mean & 3 & 4 & 5 & 2 & 1 \\
\hline \multirow{2}{*}{$\begin{array}{c}\text { Optimum } \\
\text { Level }\end{array}$} & SN Ratio & 4 & 4 & 3 & 1 & 4 \\
\cline { 2 - 7 } & Mean & 5 & 4 & 2 & 1 & 4 \\
\hline $\begin{array}{l}\text { Adjustme } \\
\text { nt }\end{array}$ & Varia & Mility & Mean & $\begin{array}{c}\text { Varia } \\
\text { bility }\end{array}$ & $\begin{array}{c}\text { Varia } \\
\text { bility }\end{array}$ & Mean \\
\hline $\begin{array}{l}\text { Optimum } \\
\text { Combinat } \\
\text { ion }\end{array}$ & & A4 & B4 & C3 & D1 & E4 \\
\hline
\end{tabular}

Table 9. ANOVA table for MRWSN: Case study-1

\begin{tabular}{|c|l|c|c|c|}
\hline Code & $\begin{array}{c}\text { Factor( } \\
\text { GA } \\
\text { Parameter } \\
\text { ) }\end{array}$ & $\begin{array}{c}\text { Degree } \\
\text { of } \\
\text { Freedo } \\
\mathbf{m}\end{array}$ & $\begin{array}{c}\text { Sum of } \\
\text { Square } \\
\text { Total }\end{array}$ & $\begin{array}{c}\text { Percent } \\
\text { Contribution } \\
(\mathbf{\%})\end{array}$ \\
\hline A & $\begin{array}{l}\text { Population } \\
\text { Size }\end{array}$ & 4 & 1.604 & 27.57 \\
\hline B & $\begin{array}{l}\text { Fitness } \\
\text { scalling } \\
\text { Function }\end{array}$ & 4 & 0.524 & 9.01 \\
\hline C & $\begin{array}{l}\text { Selection } \\
\text { Function }\end{array}$ & 4 & 0.931 & 16.00 \\
\hline D & $\begin{array}{l}\text { Mutation } \\
\text { Function }\end{array}$ & 4 & 0.564 & 9.70 \\
\hline E & $\begin{array}{l}\text { Crossover } \\
\text { Function }\end{array}$ & 4 & 2.194 & 37.72 \\
\hline & Total & 20 & 5.817 & 100 \\
\hline
\end{tabular}


Table 10. ANOVA table for - overall desirability (OD) : Case study-2

\begin{tabular}{|c|l|c|c|c|}
\hline Code & $\begin{array}{c}\text { Factor( GA } \\
\text { Parameter) }\end{array}$ & $\begin{array}{c}\text { Degree of } \\
\text { Freedom }\end{array}$ & $\begin{array}{c}\text { Sum of } \\
\text { Square } \\
\text { Total }\end{array}$ & $\begin{array}{c}\text { Percent } \\
\text { Contribu } \\
\text { tion ( \% ) }\end{array}$ \\
\hline A & $\begin{array}{l}\text { Population } \\
\text { Size }\end{array}$ & 4 & 0.03 & 16.30 \\
\hline B & $\begin{array}{l}\text { Fitness scaling } \\
\text { Function }\end{array}$ & 4 & 0.018 & 9.78 \\
\hline
\end{tabular}

\begin{tabular}{|c|l|c|c|c|} 
C & $\begin{array}{l}\text { Selection } \\
\text { Function }\end{array}$ & 4 & 0.01 & 5.43 \\
\hline $\mathrm{D}$ & $\begin{array}{l}\text { Mutation } \\
\text { Function }\end{array}$ & 4 & 0.043 & 23.37 \\
\hline $\mathrm{E}$ & $\begin{array}{l}\text { Crossover } \\
\text { Function }\end{array}$ & 4 & 0.083 & 45.11 \\
\hline \multicolumn{2}{|l}{ Total } & 20 & 0.184 & 100 \\
\hline
\end{tabular}

Table 11: best fitness - comparison between predicted design and confirmation run

\begin{tabular}{|c|c|c|c|c|c|c|c|c|c|c|}
\hline \multirow{2}{*}{ Case Study } & \multirow{2}{*}{ GA Setting } & \multicolumn{5}{|c|}{ GA Parameter Combination } & \multicolumn{2}{|c|}{ Prediction } & \multicolumn{2}{|c|}{ Confirmation } \\
\hline & & $\mathbf{A}$ & B & $\mathbf{C}$ & D & $\mathbf{E}$ & SN Ratio & Mean & SN Ratio & Mean \\
\hline \multirow{2}{*}{$\begin{array}{c}\text { Case Study } 1 \\
\text { (Experimental } \\
\text { Data : MRWSN ) }\end{array}$} & Default Settings & 1 & 1 & 1 & 1 & 1 & & & 38.344 & 33.398 \\
\hline & $\begin{array}{l}\text { Optimal Combinations / } \\
\text { Best Settings }\end{array}$ & 5 & 3 & 2 & 5 & 4 & 68.142 & 34.996 & 59.158 & 34.227 \\
\hline \multirow{2}{*}{$\begin{array}{c}\text { Case Study } 2 \text { ( } \\
\text { Historical Data : } \\
\text { Over All } \\
\text { Desirability) }\end{array}$} & Default Settings & 1 & 1 & 1 & 1 & 1 & & & 18.525 & 0.672 \\
\hline & $\begin{array}{l}\text { Optimal Combinations / } \\
\text { Best Settings }\end{array}$ & 4 & 4 & 3 & 1 & 4 & 23.593 & 0.794 & 28.540 & 0.751 \\
\hline \multirow{2}{*}{ Improvement } & Case Study 1 & & & & & & & & $54.3 \%$ & $24.8 \%$ \\
\hline & Case Study 2 & & & & & & & & $54.1 \%$ & $11.7 \%$ \\
\hline
\end{tabular}

\section{CONCLUSIONS}

This paper presents a methodology for Genetic Algorithm parameter optimization with the application of two case studies. The conclusions are as follows:

1. The findings of this study clearly shows the robust optimization of GA parameters leading to the best level of performance characteristics with least variability for the real life optimization problem, using Taguchi Experimental Design Techniques.

2. The experimental results show that there is an increase of signal-to-noise ratio (SNR) by $54 \%$ and mean by 12 to $25 \%$ from the default setting of GA to the optimum settings arrived during the experimental process. These are extremely significant.

3. The proposed approach successfully provides the best setting of GA parameters only with the 25 set of experiments at against 3125 number of full factorial experiments for each case study, at which the model outcome is best in performance and less sensitive to variations in noises.

4. The cross over operator is found to be the most influential parameter in both the case studies, followed by mutation rate, population size for case study-1 and population size and selection process for case study-2. It is evident that the robust GA parameter settings are sensitive to the objective function (transfer function in GA terms).

5. The confirmation experiments proved that the determined optimal combination of GA parameters satisfy the real requirements of the Best fitness value with least variation.
6. The default settings of MATLAB GA internal control parameters are not really the optimum one for both the cases, with respect to the desired response and various noises.

7. The findings clearly indicate that the proposed research method for GA parameter optimization is general enough to adopt and apply for wide varieties of applications in MATLAB or any other GA environments. It is recommended that the researchers use it for best performance.

\section{REFERENCES}

[1] D. E. Goldberg, Genetic algorithms in search, optimization and machine learning. Reading, MA: Addison- Wesley,1989.

[2] Chakraborty, U., Deb, K., and Chakraborty, M. (1996). Analysis of selection algorithms: A Markov chain approach. Evolutionary Computation,(2).132-167.

[3] Kalyanmoy Deb and Samir Agrawal , Understanding Interactions among Genetic Algorithm Parameters, KanGAL Report Number 1999003

[4] Avni Rexhepi, Adnan Maxhuni, Agni Dika, Analysis of the impact of parameters values on the Genetic Algorithm for TSP,IJCSI International Journal of ComputerScience ssues,Vol.10,Issue1,No3,January 2013

[5] Farhad Kolahan, Marziyeh Hassani Doughabadi, The effects of parameter settings on the performance of Genetic Algorithm through experimental design and statistical analysis , 2011 2nd International Conference on Mechanical, Industrial, and Manufacturing Technologies (MIMT 2011) 
[6] Rezende, M. C. A. F., Costa, A. C., Maciel Filho, R., Bártolo, P. J. S., Rezende, R. A. A systematic procedure to set up the genetic algorithm parameters for large scale systems: application to a three phase catalytic reactor ,CP 6066, CEP 13087-970, Campinas-SP, Brazil

[7] A. L. Haines , K. L. Mills, J. J. Filliben, Determining Relative Importance and Best Settings for Genetic Algorithm Control Parameters, 200X by the Massachusetts Institute of Technology , Evolutionary Computation Volume $\mathrm{x}$, Number $\mathrm{x}$

[8] Richard Myers, Edwin R. Hancock, Genetic algorithm parameter sets for line labeling, Elsevier, Pattern Recognition Letters 18_1997.1363-1371

[9] Eric Pellerin, Luc Pigeon, Sylvain Delisle, Self-Adaptive Parameters in Genetic Algorithms , Defence R\&D Canada (DRDC Valcartier), Université du Québec à Trois-Rivières, Québec, Canada, G9A 5H7

[10] Calin Florin Baban, Marius Baban, Ioan Eugen Radu, University of Oradea, Reliability Improvement of Deformation Tools with The Taguchi Robust Design , 14244-1461-X/08/\$25.00 @2008 IEEE
[11] Srinivas Athreya, Dr Y.D.Venkatesh , Application Of Taguchi Method For Optimization Of Process Parameters In Improving The Surface Roughness Of Lathe Facing Operation , International Refereed Journal of Engineering and Science (IRJES) ISSN (Online) 2319-183X, (Print) 2319-1821 Volume 1, Issue 3 (November 2012), PP.13-19

[12] J.G.Che, G. M Xian, and M. knod, An Integrated Design Method of New Product and the Production Process Based on Taguchi Robust Design, 2007 IEEE

[13] S. Kamaruddin , Zahid A. Khan and SH Foong, Application of Taguchi Method in the Optimization of Injection Molding Parameters for Manufacturing Products from Plastic Blend, Intl Journal of Engineering and Technology, Vol2, No6 ,Dec 2010

[14] Abhishek Majumdar, Dr A Ramesh , An application of Taguchi Robust Optimization Design for development of a new product in Manufacturing space, International conference of operation management at IIT Roorkee,Dec12-14, 2014 